performing wedge resection. However, at the time, complete resection would not have been possible unless both sides had been approached.

Single port resection of a benign rib tumor is feasible and can be done with readily available instruments (Figure 2, $B$ ). The advantages of thoracoscopic methods have been previously reported. ${ }^{3}$ These advantages include a smaller incision, no muscle damage, and no dead space issues, which can lead to complications. Other advantages include a more rapid recovery to daily life and a shorter hospital stay. One-port methods have the same advantages, with the addition of resulting in a single scar, instead of 3 . Thus, the occurrence of pain can be reduced. The procedure itself is simple and straightforward, using readily available instruments without the complex instruments necessary for a more complex procedure. Our patient was doing well and was satisfied with her outcome at the last follow-up visit.

\section{References}

1. Jabra AA, Fishman EK. Eosinophilic granuloma simulating an aggressive rib neoplasm: CT evaluation. Pediatr Radiol. 1992;22:447-8.

2. Chon SH, Lee CB, Shinn SH, Heo JN, Paik SS. Rib xanthoma resected by video-assisted thoracoscopic surgery using a bone punch. Surg Laparosc Endosc Percutan Tech. 2009;19:e15-6.

3. Shim JH, Chon SH, Lee CB, Heo JN. Polyostotic rib fibrous dysplasia resected by video-assisted thoracoscopic surgery with preservation of the overlying periosteum. J Thorac Cardiovasc Surg. 2010;140:938-40.

\title{
Maximized left atrial dome approach for left atrial tumor resection
}

\author{
Syed T. Hussain, MD, ${ }^{\mathrm{a}}$ Mazin Alsalihi, MD, ${ }^{\mathrm{a}}$ Eugene H. Blackstone, MD, ${ }^{\mathrm{a}, \mathrm{b}}$ and \\ Gösta B. Pettersson, MD, PhD, ${ }^{a}$ Cleveland, Ohio
}

Video clip is available online.

Despite their rarity, cardiac tumors can present a technical challenge, both diagnostically and with regard to surgical approach and resection. Complete surgical resection remains crucial for palliation of symptoms and for its role as the mainstay of cardiac sarcoma therapy ${ }^{1-3}$ Because of difficult access in attempting complete resection of sarcomas involving the left atrium (LA), surgeons have used cardiac autotransplantation and ex vivo tumor resection with cardiac reconstruction and reimplantation. ${ }^{3-5}$ We describe an alternative, compromise technique to approach these tumors by maximizing exposure with a modified LA dome approach.

\footnotetext{
From the Department of Thoracic and Cardiovascular Surgery, ${ }^{\mathrm{a}}$ Heart and Vascular Institute, Cleveland Clinic, Cleveland, Ohio; and the Department of Quantitative Health Sciences, ${ }^{\mathrm{b}}$ Research Institute, Cleveland Clinic, Cleveland, Ohio.

Disclosures: Authors have nothing to disclose with regard to commercial support.

Received for publication April 16, 2014; revisions received April 16, 2014; accepted for publication May 2, 2014; available ahead of print June 6, 2014.

Address for reprints: Gösta B. Pettersson, MD, PhD, Department of Thoracic and Cardiovascular Surgery, Cleveland Clinic, 9500 Euclid Ave, Desk J4-1, Cleveland, OH 44195 (E-mail: petterg@ccf.org).

J Thorac Cardiovasc Surg 2014;148:748-50

0022-5223/\$36.00

Copyright (c) 2014 by The American Association for Thoracic Surgery

http://dx.doi.org/10.1016/j.jtcvs.2014.05.002
}

\section{CLINICAL SUMMARY}

A 50-year-old symptom-free patient with a history of smoking and diabetes was seen for a LA mass discovered on echocardiography, indicated by a cardiac murmur on routine physical examination. The echocardiogram (Figure 1, A, Video 1) showed a large, irregular, multilobed mass continuous with the LA medial and lateral walls and protruding through the mitral valve leaflets, causing mitral stenosis and regurgitation. Magnetic resonance imaging of the heart (Figure 1, B) confirmed the mass $(3.3 \times 2 \times 1.7$ $\mathrm{cm})$ in the LA, with central low signal, correlating with the calcifications on computed tomographic scan (Figure 1,C). The tumor was extensive, with some features suggesting malignancy, but was still noninvasive on imaging. The coronary arteries were shown to be normal on cardiac catheterization. The tumor was supplied by a branch of the right coronary artery and was well vascularized.

For surgery, after median sternotomy, aortic and bicaval cannulations were performed, with the superior vena cava (SVC) cannulated high. The SVC, aorta, and pulmonary artery were divided, and the LA was widely opened with an incision that was started anterior to the right pulmonary veins, carried behind the SVC, continued along the upper edge of the roof of the LA, and ended anterior to the left pulmonary veins (Figure $2, A$ and $B$ ). This provided excellent exposure of the entire LA and the fibrous endocardial tumor, which covered a large portion of the LA and mitral valve. The tumor was easily peeled off, along with the endocardium of the LA (Figure 3), but was firmly attached to both valve leaflets, which were 

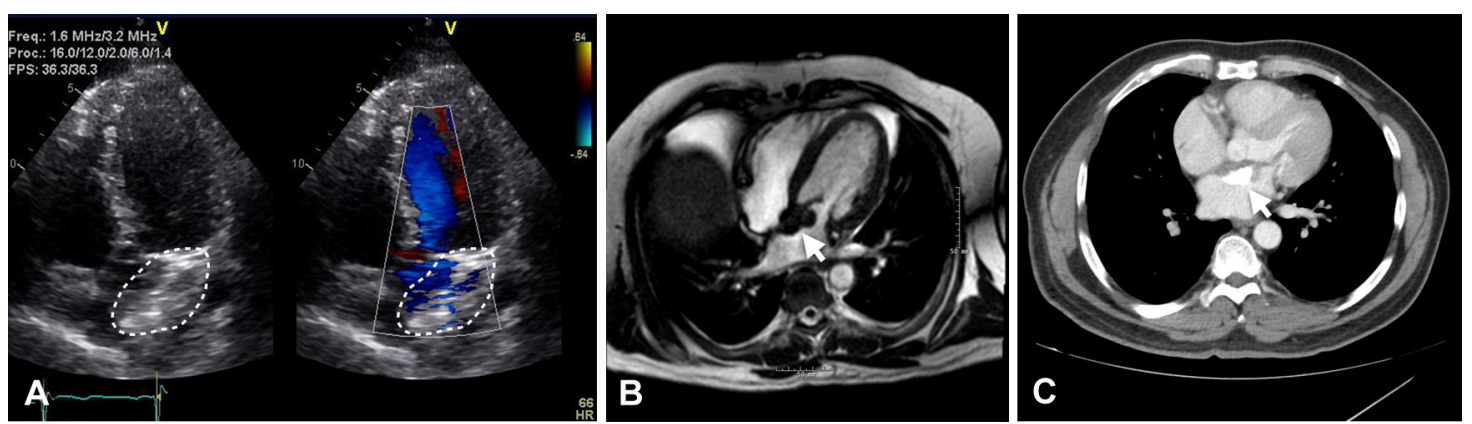

FIGURE 1. The left atrial tumor as depicted by various imaging modalities. A, Echocardiogram (dotted area); B, Magnetic resonance imaging (arrow); C, Computed tomographic scan (arrow).
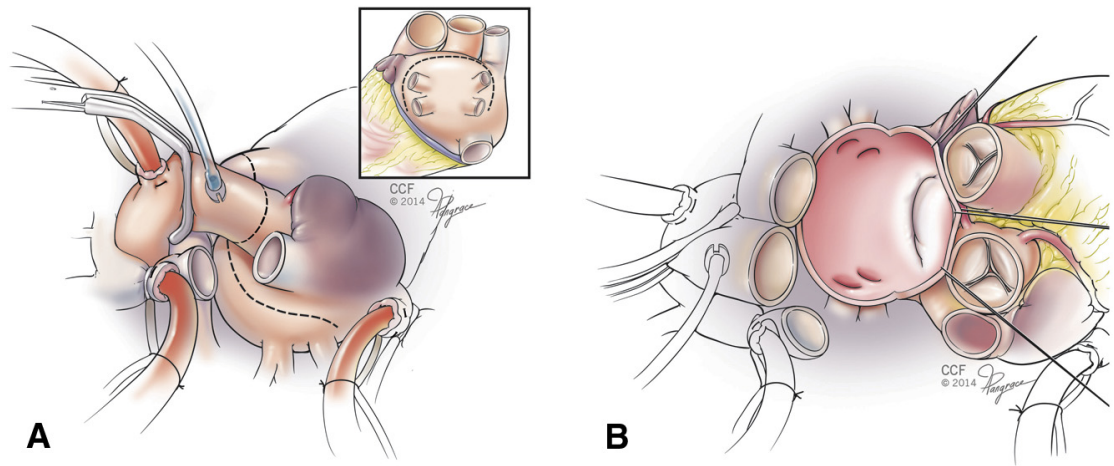

FIGURE 2. Diagram showing the surgical approach. A, Incision lines for the modified dome approach to the left atrium. B, The superior vena cava, aorta, and pulmonary artery have been divided for improved access to the left atrium and mitral valve.

also resected. The valve was replaced with a mechanical valve. The LA appendage was removed, the LA incision was primarily closed, and the pulmonary artery, aorta, and SVC were reconnected.

The patient had an uneventful postoperative recovery. The final histologic diagnosis was extraosseous osteosarcoma with chondrosarcomatous elements (grade 3), multifocal tumor nodules, and endocardial spread involving the

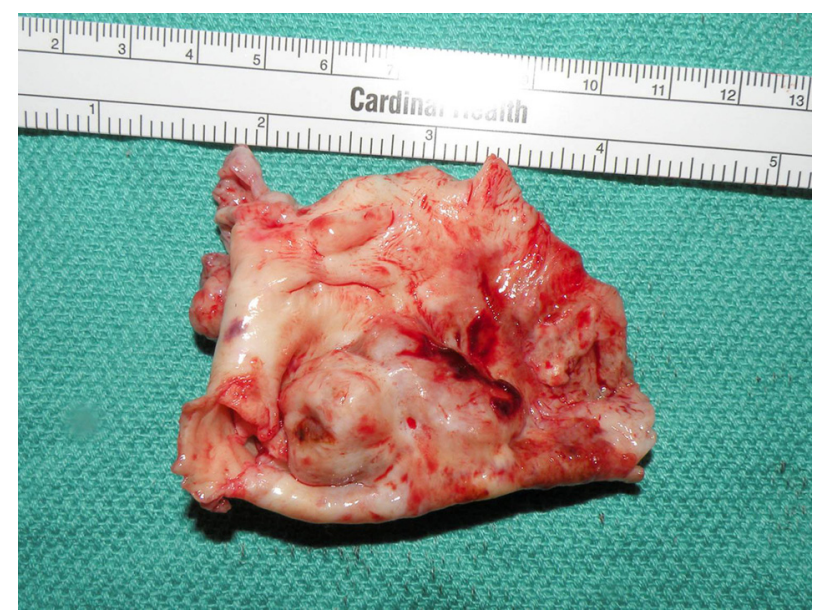

FIGURE 3. Excised left atrial tumor.
LA, the LA appendage, and the mitral valve and chordae. The patient was scheduled for combined chemotherapy and radiation therapy.

\section{DISCUSSION}

Cardiac sarcomas are aggressive and locally invasive. Complete surgical resection remains the mainstay of definitive treatment and effective palliation of primary cardiac sarcomas, along with multimodal treatment consisting of adjuvant chemotherapy, radiation therapy, or both. ${ }^{1-3}$ Our patient had a large tumor involving a large portion of the LA and mitral valve. Resection required complete exposure of the entire LA, which we accomplished through our maximized LA dome approach. Several surgeons have previously reported using autotransplantation for LA tumors. ${ }^{3-5}$ Taking the heart completely out for ex vivo tumor resection would not have offered additional exposure, however, because we already had excellent exposure of the entire LA, the tumor, and the mitral valve. Myocardial protection was secured by retrograde cardioplegia given through a cannula placed openly and directly into the coronary sinus through a purse-string suture. The tumor turned out to be easy to peel off the atrial wall, although it was firmly attached to the valve leaflets. 
Our maximized dome approach for an LA tumor provided perfect exposure. This approach may also be useful as an alternative to autotransplantation in other situations calling for complete LA exposure.

\section{References}

1. Hamidi M, Moody JS, Weigel TL, Kozak KR. Primary cardiac sarcoma. Ann Thorac Surg. 2010;90:176-81.
2. Isambert N, Ray-Coquard I, Italiano A, Rios M, Kerbrat P, Gauthier M, et al. Primary cardiac sarcomas: a retrospective study of the French Sarcoma Group. Eur J Cancer. 2014;50:128-36.

3. Bakaeen FG, Jaroszewski DE, Rice DC, Walsh GL, Vaporciyan AA, Swisher SS, et al. Outcomes after surgical resection of cardiac sarcoma in the multimodality treatment era. J Thorac Cardiovasc Surg. 2009;137:1454-60.

4. Cooley DA, Reardon MJ, Frazier OH, Angelini P. Human cardiac explantation and autotransplantation: application in a patient with a large cardiac pheochromocytoma. Tex Heart Inst J. 1985;12:171-6.

5. Reardon MJ, Malaisrie SC, Walkes JC, Vaporciyan AA, Rice DC, Smythe WR, et al. Cardiac autotransplantation for primary cardiac tumors. Ann Thorac Surg. 2006;82:645-50 